R E S E Ñ A

\title{
Los de China no son cuentos
}

\author{
Rolando Cordera Campos
}

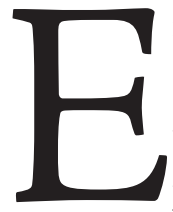

$\mathrm{n}$ medio de convulsiones que anuncian revoluciones de signo incierto, China se conmueve con el cambio de su dirigencia política, mientras desde las cumbres del poder se advierte la necesidad de realizar, pronto, una reforma política de gran calado. No es para menos. Repentinamente, al menos en términos de su historia milenaria, el país continente que encaró a la Unión de Repúblicas Soviéticas Socialistas (URSS) y pretendió el liderazgo de la revolución mundial, para luego desatar una ola que parecía interminable de movilización social y cultural que proclamaba una suerte de revolución total bajo la tutela de su «Gran Timonel», Mao Tse Tug, se revela como una gran potencia emergente, modifica traumáticamente su pauta de crecimiento y se ve obligada a preguntarse ahora, en medio de una profunda crisis global, acerca de los caminos que puede seguir o inventar para no sólo crecer sino desarrollarse como sociedad moderna. Nada más ni nada menos.

Este portentoso laboratorio humano de fuerzas productivas que se tornó poderosa máquina de expansión industrial, hoy es visto no sólo como el «taller del mundo», sino como una realidad peligrosa para los magros equilibrios finan- 
cieros y comerciales globales. Del sustento dinámico de estos equilibrios depende, en medida creciente, la estabilidad de una globalización que no genera crecimiento sino incertidumbre abrumadora y pérdida progresiva de horizontes y expectativas para vastos continentes humanos y productivos. $Y$ en medio de este Armagedón implacable aparece el viejo Reino del Centro pletórico de potencialidades constructivas a la vez que destructivas, de sus propios tejidos, estructuras y jerarquías, pero también que dan sustento al capitalismo más avanzado.

Desde estos complejos panoramas históricos e intelectuales, Víctor López Villafañe, en su libro La modernidad de China. Fin del socialismo y desafíos de la sociedad de mercado (Siglo xxi Editores, México, 2012), se arriesga a elaborar una síntesis atractiva y a trazar una perspectiva problemática sobre el gran experimento chino que ha marcado con fuerza inaudita los escenarios de un desarrollo diferente, pero no exento de gestar nuevas y viejas contradicciones, propias de los sistemas económicos organizados en torno al mercado y la ganancia. Expuesto en cinco densos capítulos, una atractiva introducción, un desafiante epílogo y dos sabrosos anexos (uno de entrevistas hechas en Beijing y otro de personajes de Beijing, un acierto), el libro de López Villafañe constituye un valioso aporte a nuestro conocimiento de la China del presente.

Como bien lo ilustra nuestro autor, este conocimiento es inimaginable sin hundirnos en una historia milenaria que a lo largo del siglo pasado adquirió especial intensidad y dinamismo, pasó por convulsiones mayúsculas que pusieron al país entero al borde de un precipicio sin fin y luego dieron paso a una modernización peculiar, idiosincrática podría decirse, que ha desembocado en una transformación productiva y social alucinante.

En pocas páginas, Víctor nos ofrece una síntesis magnífica que debe leerse con atención y puede hacerse con gusto, y desde luego discutirse acuciosamente, entre otras razones porque el chino constituye un experimento vivo de desarrollo y cambio en la globalización, promisorio y ominoso como lo es siempre toda aventura desarrollista, cargado de lecciones e inspiraciones para enfrentar nuestras propias tribulaciones. Muy bienvenido sea este nuevo logro de Víctor en su ya rica incursión por el otrora misterioso Oriente. 
Modernizar la modernización sin renunciar al robusto legado milenario: más allá del socialismo y de lleno en la sociedad de mercado, nos propone el libro: ¿es ésta la saga china, su destino manifiesto, a partir de las reformas de Deng Xiaoping? ¿Puede resumirse así una historia tan compleja como la del territorio donde se asentó el «Reino del medio» y ahora se desafía desde la economía más dinámica imaginable a la vista, el hegemón occidental radicado en América del Norte?

Se trata, como lo plantea casi obsesivamente nuestro autor, de una modernidad que emerge de lo antimoderno, como lo definiría cualquier profesor occidental, cuando no un político del poder americano. Peliagudo conceptualmente, el tema se llena de historia y nos refiere al aspecto fundamental de la modernidad, cualesquiera sean sus apellidos: ¿qué pasa o debe pasar con el Estado?, ¿de qué tipo o morfología estatal debe o puede hablarse para darle a esta modernidad una impronta históricamente específica que pueda concebirse como realidad andante en una época de «alta globalidad»?, ¿será el experimento chino el paradigma venidero para la utópica y destructiva ilusión de un mercado mundial unificado sin Estado?, ¿cómo, para ir a lo más concreto e inmediato, lidiar con los «desafíos de la sociedad armoniosa» que el autor sintetiza con precisión en su capítulo inicial? (López Villafañe, 2012: 21-26). Más complicado aún: ¿cómo imaginar la transición a una economía de mercado y, a la vez, asumir productivamente la «contradicción crónica de la sustentabilidad» que, según Víctor, es la que fundamentalmente determinará el futuro de China? Como concluye tajantemente su capítulo sobre la transición a la economía de mercado: «los intereses de la clase media china conducen tanto a una democratización política como a un desastre ecológico» (ibid., p. 73).

Para dar un ejemplo de la dificultad creativa a que nos convoca la reflexión de Víctor, en el epílogo, al reiterar lo planteado al principio del texto sobre una de las claves poderosas, pero no por ello menos enigmáticas, el espectacular desarrollo chino, postula: «la combinación de formas mercantiles muy poderosas, pero reprimidas, a lo largo de la historia de China, y liberadas 
por las nuevas políticas del Estado desde 1978 para promover las relaciones de mercado capitalistas, han sido factores esenciales de la transformación sorprendente de China» (ibid., p. 57). Nada más y nada menos: la combinación de lo viejo con lo nuevo para dar como fruto lo moderno. Una proeza, pero a la vez un desafío en términos de la continuidad sostenida del complejo proyecto.

El gran enigma para el futuro, pero sin duda también el gran dilema que la dirigencia china se ha planteado en tiempos recientes, es el papel del Estado como palanca fundamental no sólo del crecimiento sino del desarrollo, de la transformación productiva y social, pero también el Estado como conjunto institucional articulado autoritariamente frente a una sociedad que cambia con celeridad, se urbaniza y se asoma al mundo. La escena para una tragedia del desarrollo, como Hirschman resumió el 68 mexicano, está puesta, a pesar de que la matanza de Tiananmen haya sido una señal clara de que la reforma iba por la economía y no por la política. El conflicto distributivo ya está planteado, pero su dimensión es del tamaño de la magnitud productiva, y sólo en una combinación virtuosa de crecimiento y redistribución es concebible la durabilidad de un equilibrio político social funcional a un crecimiento como el chino. Aquí, la obligada conversación entre acumulación y distribución, siempre acosada por el propio cambio técnico y económico, adquiere una intensidad pasmosa y le da a la reforma política una relevancia sin duda histórica.

El término capitalismo de Estado que nuestro autor sugiere para clasificar a China no es, al parecer, una categoría inmutable ni inmune a las convulsiones de la sociedad que, a su manera, se filtran hacia la rígida pirámide del poder comunista. El modo y los ritmos de su ampliación a una participación deliberativa, que pudiera dar lugar a estructuras democráticas formales, engrosan esta combinación de dilemas y enigmas que definen la encrucijada china. Como lo escribe Víctor López Villafañe: «El tema central de la dirigencia china está ahora más enfocado al equilibrio y la "armonía social”». La transición de China - que debe entenderse todavía como un largo camino hacia el futuro- estará en los próximos años sometida a tensiones y fuerzas contradictorias, en lo nacional y lo internacional. 
Concluye: «se trata de un proceso histórico lleno de complejidades e incertidumbres sobre el que debemos mantener nuestra atención, para poder vislumbrar el camino por el que se desplazará esta modernidad de China» (ibid., p. 161).

El excelente relato de Víctor López Villafañe, donde se ponen en movimiento años de estudios, reflexión y vivencias en China, termina con una pregunta acuciante: «Whither China?» ¿A dónde va la China que mira y vuelve a mirar su historia y sus pretensiones seculares de ser el centro del mundo? $¿$ A dónde se dirige este coloso real y actual, donde se concentran las reservas monetarias del mundo, se teje y desteje a diario el futuro de la deuda estadounidense, y se crea y recrea la fábrica mundial de manufacturas que, en gran proporción, han llegado a conformar el nuevo núcleo de los bienes salario del proletariado del mundo más avanzado?

Sin dejar por un momento de reconocer el valor de este trabajo, quisiera insistir: ¿el mero tránsito del socialismo al estilo chino a una economía de mercado asegura el surgimiento de los mecanismos de ajuste y equilibrio que un Golem como el chino demanda para tan sólo asegurar su reproducción y supervivencia? La enorme aspiradora de alimentos, materias primas, inversión foránea y tecnología que hoy representa China, ¿es concebible dinámicamente a partir de la asimilación de los criterios de la economía de mercado? Más aún: el gran edificio étnico y demográfico que es y será China, ̨es sustentable $y$, repito, reproducible, en el marco institucional derivado de esta sociedad de mercado que nuestro autor ve como una realidad presente y en desarrollo?

Un punto más que el autor aborda en varios de sus espléndidos capítulos: ¿qué con la ideología? La modernización como Santo Grial, pero también como la inspiración fundamental para ir más allá de la racionalidad occidental que condensa la historia misma de la modernidad como la hemos entendido, vivido, buscado. La contradicción que Víctor resalta es central, porque en realidad nos habla de una suerte de enorme incongruencia histórica. Si hubiera que adelantar una hipótesis sobre el despliegue de esta contradicción o incongruencia, habría que decir que ha sido el Partido Comunista Chino el 
vector de dinamización, modulación y represión de esta tensión y que en el horizonte no se vislumbra un sucedáneo eficaz de este portentoso mecanismo de inclusión y dominación que encabeza, resiste, desvía y vuelve a recuperar las señas de identidad de una modernización que aspira a desembocar en una modernidad «al estilo chino», a falta del actual socialismo de mercado también al «estilo chino» (recordemos a Skidelsky y su dignatario comunista).

La china es la historia contemporánea de una gran modernización que desemboca en un despampanante desarrollo, entendido como cambio social en gran escala. Éste es el punto de partida bien estudiado y comprendido por Víctor, y hoy objeto de curiosidad e investigación intensas de parte de los estudiosos chinos alojados en sus varias academias de ciencias. Alcanzado el punto máximo del panorama trazado por Arthur Lewis, cerca de los puntos de inflexión de la célebre curva de Kuznets, ¿hacia dónde ir? y ¿cómo?

El trabajo de Víctor López Villafañe se inscribe en la rica serie de ensayos e informes de investigación destinados a construir las hipótesis y trazar las posibles trayectorias de un gigante, un Pantagruel, que se dirige a paso largo a reconfigurar los equilibrios conocidos del poder y la economía política internacional; ahora, además, acorralado por una crisis global cuya salida nadie acierta a pronosticar o concebir. ¿Serán los tumbos de este coloso, al topar con las realidades duras del desequilibrio permanente de la economía de mercado, los que abran las puertas de alguna solución cooperativa que aminore los costos y acreciente las perspectivas de ganancias compartidas?

Estas preguntas y especulaciones, junto con otras similares o dispares, me las ha provocado la lectura de este bien confeccionado y pensado relato histórico sobre el presente y el porvenir de la China fulgurante y eterna. Hay que leerlo y masticarlo, porque habla, y mucho, de nuestro futuro como habitantes del mundo y como actores un tanto resignados de una globalización cuyas coordenadas principales serán definidas, para bien y para mal, por los modos como ese país resuelva o no sus acertijos históricos irremediablemente globales.

Si se trata de hablar de encrucijadas planetarias, nada como China puede llenar nuestras fantasías... Cargadas de potenciales pesadillas. 